\title{
Optimal Portfolio of Basic Pension Insurance Funds in China
}

\author{
Hao Li \\ Shandong University of Finance and Economics, School of Insurance, China,250014
}

\begin{abstract}
China's pension fund has a large amount of capital, and the investment direction of the fund has a certain impact on the capital market. A good portfolio can promote the healthy development of the real economy. With the continuous change of capital market, new financial products emerge and the operating ability of listed companies change ceaselessly, so that the portfolio of pension funds needs to be changed from time to time. In this paper, initially, with the help of consistent risk measurement theory, it is shown that CVaR has better properties than VaR and other risk measurement tools. Then the paper selects the daily rate of return of bank deposit, Shanghai, Shenzhen, Shanghai and Shanghai bonds, and the daily rate of return of the Shanghai Stock Exchange Fund. At last, the combination of the pension investment based on CVaR is obtained by using the Matlab.
\end{abstract}

Keywords: Pension insurance fund; CVaR; investment portfolio

\section{Introduction}

According to the data of the National Bureau of Statistics of China, by the end of 2018, the total population of China is 1.395 billion, and the working population is 897 million which account for $64.3 \%$. The elderly population (over 60 years of age) is 249 million, accounting for $17.9 \%$. Internationally, the proportion of the population over 60 years of age is more than $10 \%$ of the total population, or the proportion of the population over 65 years of age is more than $7 \%$ as the standard for countries or regions to enter an aging society.By this standard, China has entered an ageing society since 2000 . The core problem of aging society is pension problem whose key is the use of pension fund.

At present, the main sources of income of China's basic pension funds are premium collection income, central and local financial subsidies, investment income. According to the data of recent years, the changes of these three income ratios are different, and the proportion of premium collection income has decreased year by year, from $84 \%$ in 2005 to $76 \%$ in 2018 . On the contrary, the proportion of central and local financial subsidies has increased year by year, from $13 \%$ in 2005 to $19 \%$; while the proportion of investment income has remained stable, fluctuating around $5 \%$ in recent years.From the above data, there is no income and expenditure gap in China's pension funds. However, if we consider the "bottom" nature of fiscal subsidy funds and eliminate the government financial subsidies, we will find that since 2015, there has been an obvious funding gap, and the gap is gradually increasing. The improvement of fund gap can not only expect government subsidies, which will not only solve the problem but also increase the financial burden. Therefore, it is urgent to promote the maintenance and appreciation of pension funds and expand the scope of operation and investment of pension funds.

Although the Chinese government invests in basic pension funds, in order to avoid risk, bank deposits account for the largest proportion of most investments, and the average annual return on investment of the funds is only about $5 \%$, which is far from enough. In addition, with the continuous changes in the capital market, new financial products continue to emerge, and the operating ability of listed companies is constantly changing, so that the portfolio of pension funds also needs to be changed from time to time. Therefore, based on the above background, this paper focuses on exploring the investment portfolio of pension funds in China, which is of great significance to the investment operation of the fund, which is helpful to increase the investment income of the fund and solve the problem of maintaining the value of the fund, thus it can weaken the impact of aging and fund gap on the pension fund.Moreover, the pension fund has a large amount of capital, and the investment direction of the fund has a certain impact on the capital market. A good portfolio can not only stabilize the market, but also give full play to the resource allocation function of the capital market, guide the factors of production to industries and enterprises with strong management ability, and promote the healthy development of the real economy.

Scholars at home and abroad have done a lot of research on CVaR model and the optimal portfolio of pension funds. In 1952, the mean-variance model theory was put forward by Markowitz.H.M. and now the portfolio of investment theory is formally formed. Jose A.Lopez (1997) put forward the financial risk measurement tool VaR. Rockafellar, Stanislav (1999) proposed the CVaR risk welfare tool, which laid the foundation for the pension fund investment in the capital market. Teodoras Medaiskis (2017) assessed the supply and investment strategy of the 
Baltics Pillar II pension fund and concluded that stricter rules were needed to develop the pension fund investment strategy and to establish a link with the age of the participants in order to improve the compatibility between the supply of the fund and the needs of the participants throughout the life cycle. Ling Zhang (2018) studied the optimal multi-period investment management of fixed contribution pension funds under the mean-variance criterion with imperfect information. The numerical results showed that the imperfection of market state information might lead to the loss of investment income. Alserda, Bikker (2018) introduced new estimates of pension economies of scale. Ruan Xiang (2018) provided valuable inspiration for the practice of pension fund investment in China by comparing the experience of infrastructure investment in Canada, Australia, Latin America and other countries. Margarita Gelepithis (2019) takes the United Kingdom as an example, reevaluates the role of financial professionals in pension fund investment strategies, and puts forward the argument that the changes in the allocation of pension fund assets reflect the independent impact of the network of investment professionals, who have constructed and institutionalized debt-driven investment norms.Based on the previous research, this paper studies the optimal portfolio of China's basic pension fund by using CVaR risk measurement model.

\section{Model Selection}

$V a R$, as an important risk measurement technology, is widely used in the study of portfolio investment theory. $V a R$ refers to the potential maximum loss of any financial instrument or portfolio in a given probability confidence level in a certain period of time in the future, under the normal volatility of the market.

$$
\operatorname{Pr} o b\left(f \geq \operatorname{VaR}_{\beta}\right)=1-\beta
$$

$f$ represents the loss of the portfolio during the holding period; $\operatorname{VaR}_{\beta}$ is the portfolio at the confidence level The value of being at risk.

However, VaR has a large defect, mainly in the following aspects: First of all, it is reflected in the calculation method of VaR. Although there are many ways to calculate VaR, the calculation results of various methods vary greatly,which makes us doubt the usefulness of the results. Secondly, VaR does not satisfy the sub-additivity, which makes it impossible for financial institutions to deduce the $\mathrm{VaR}$ of the whole financial institution by calculating the VaR of each branch. Finally, there is nothing VaR can do to prevent some extreme events. Although the probability of extreme events is very small, once they occur, financial institutions will suffer huge losses.

In order to avoid the weakness of VaR, Duffie and Pan (1997) put forward the concept of CVaR (Conditional Value-at-risk), which means the loss of a portfolio is greater than the average loss value under a given VaR value.

$$
\left.\operatorname{CVaR}_{\beta}(x)=E\left\{f(X, P(t)) \mid f(X, P(t)) \geq \operatorname{VaR}_{\beta}(x)\right)\right\}
$$

$f(X, P(t))$ represents the loss of a portfolio; $P(t)$ is the asset price at the end of the $t$ period; $X \in \pi$ is investment portfolio; It not only has the advantages of VaR, but also satisfies the risk measurement of subadditivity, convexity and consistency. Therefore, this paper chooses Mean-CVaR model to explore the portfolio of Chinese pension funds.

Mean-CVaR model is built on the basis of mean variance model. Therefore, according to the principle of mean variance model, the Mean-CVaR model can be described as: On one hand, at a given expected rate of return Under the condition of making the risk Reach a minimum portfolio; On the other hand, at a given level of risk Under the condition of the expected rate of return, the portfolio with the largest expected rate of return.

Suppose:There are $\mathrm{n}$ different risk assets in the market, $\boldsymbol{W}_{i}$ represents the weight of the investor's choice of type i assets, so that $W=\left(w_{1}, W_{2}, \cdots, W_{n}\right)^{T}$ represents the weight vector for investors to select $\mathrm{n}$ kinds of risky assets. $\boldsymbol{r}_{i}$ represents the expected rate of return on type $\mathrm{i}$ investment products. $r=\left(\boldsymbol{r}_{1}, \boldsymbol{r}_{2}, \cdots, \boldsymbol{r}_{n}\right)^{T}$ represents the expected rate of return vector of the portfolio. $\boldsymbol{r}_{0}$ represents the rate of return on a given portfolio. $C \operatorname{CaR} R_{\beta}$ represents the conditional risk value of the portfolio. $C \operatorname{VaR}{ }_{\beta}^{0}$ represents the risk value of a given portfolio condition.

$$
\begin{gathered}
\min : C \operatorname{VaR}_{\beta} \\
\text { s.t. } W^{T} r \leq \boldsymbol{r}_{0} \\
\sum_{i=1}^{n} w_{i}=1 \\
\mathcal{W}_{1} \geq 0, i=1,2, \cdots, n \\
\text { or } \\
\max : \boldsymbol{r}_{p}=W^{T} r \\
\text { s.t. } C V a R_{\beta} \leq C V a R_{\beta}^{0} \\
\sum_{i=1}^{n} w_{i}=1 \\
w_{1} \geq 0, i=1,2, \cdots, n \\
C_{i} \leq w_{i} \leq D_{i}
\end{gathered}
$$


Because the returns and losses of some financial assets vary greatly, in order to protect the investment return of the portfolio and reduce the investment risk, it is necessary to limit the investment amount or proportion of some investment instruments when setting up the investment portfolio. According to the actual situation, this paper only considers that the proportion of investment in financial assets is limited here. $C_{i}$ and $D_{i}$ represent the lower and upper limits of the proportion of investments in type I financial assets respectively.

$f(x, y)$ represents the loss function of the portfolio; decision vector $x \in X$ ( $X$ is the feasible set of the portfolio and satisfies certain conditions); $x$ is the weight of risky assets; The random vector represents the market uncertainty that can affect the loss, such as a market price or rate of return. $p(y)$ is a probability density function.

$\operatorname{CVaR}_{\beta}(x)=\frac{1}{1-\beta} \int_{f(x, y) \geq \operatorname{VaR}(x)} f(x, y) p(y) d y$

Because there is a function of $V a R$ in the definition of $C V a R$, so the calculation process will be difficult to handle. Rockafellar and Uryasev $(2000,2002)$ proved that under the condition of $\alpha \in R$, the calculation of $C V a R$ could be obtained by minimizing the following auxiliary functions.

$$
F_{\beta}(x, \alpha)=\alpha+\frac{1}{1-\beta} \int_{y \in R^{m}}[f(x, y)-\alpha]^{+} p(y) d y
$$

$x^{+}=\max \{x, 0\} . C V a R$ can be obtained by minimizing $F_{\beta}(x, \alpha)$.

$$
\operatorname{CVaR}_{\beta}(X)=\min _{\alpha \in R} F_{\beta}(X, \alpha)
$$

If the analytical expression of the density function $\mathrm{p}(\mathrm{y})$ is not available, the application scenario analysis method can be used to simulate it.

Function $F_{\beta}(x, \alpha)$ can be approximately calculated:

$$
\begin{aligned}
& F_{\beta}(x, \alpha)=\alpha+\frac{1}{(1-\beta) n} \sum_{k=1}^{n}\left[f\left(x, y_{[n]}\right)-\alpha\right]^{+} \\
& =V_{a} R_{\beta}+\frac{1}{(1-\beta) n} \sum_{k=1}^{n}\left[-r_{k} w_{k}-V_{a} R_{\beta}\right]^{+}
\end{aligned}
$$

described as:

$$
\begin{aligned}
& \int \min : \operatorname{VaR}_{\beta}+\frac{1}{(1-\beta) n} \sum_{k=1}^{n}\left[-\boldsymbol{r}_{k} \boldsymbol{W}_{k}-\operatorname{VaR}_{\beta}\right]^{+} \\
& \text {s.t. } W^{T} r \leq r_{0} \\
& \sum_{i=1}^{n} w_{i}=1 \\
& w_{i} \geq 0, i=1,2, \cdots, n \\
& \int \min : V_{a} R_{\beta}+\frac{1}{(1-\beta) n} \sum_{k=1}^{n}\left[-\boldsymbol{r}_{k} \boldsymbol{w}_{k}-V_{a} R_{\beta}\right] \\
& \text { s.t. } W^{T} r \leq r_{0} \\
& \left\{\sum_{i=1}^{n} w_{i}=1\right. \\
& \boldsymbol{W}_{i} \geq 0, i=1,2, \cdots, n \\
& C_{i} \leq w_{i} \leq D_{i}
\end{aligned}
$$

\section{Empirical Study}

At present, according to the regulations of the basic pension Insurance Fund Investment Management measures, pension funds are limited to domestic investment and can not invest in foreign financial markets on a large scale. Therefore, this paper does not consider the investment in the overseas market. The domestic market investment mainly has the following four kinds of assets: bank deposits, treasury bonds, stocks, securities investment funds. Bank deposits are regarded as risk-free assets, treasury bonds, stocks and securities investment funds as three kinds of risk assets. The daily rate of return on deposits, the daily rate of return on bonds, the daily rate of return on stocks and the daily rate of return on funds are used as the historical data of investment income from January 2015 to June 2019. Bond yield and stock return series can be described by $R_{B}(t)$ and $R_{S}(t)$

$$
\text { respectively, } \quad R_{i}(t)=\log \frac{P_{i}(t)}{P_{i}(t-1)} \quad \cdot \quad R_{i}(t)
$$

represents the rate of return on the t-period index. $P_{i}(t)$ represents the closing price of the index for the $t$ period. The data selected in this article is shown in the following table.

Therefore, Mean-CVaR effective preface model can be

Chat3.1 Investment portfolio Index system of China's pension Insurance 


\begin{tabular}{c|c|c}
\hline Investment area & investment type & Measurement index \\
\hline \multirow{4}{*}{ market } & bank deposit & one-year bank deposit \\
\cline { 2 - 3 } & national debt & Shanghai national debt index \\
\cline { 2 - 3 } & equity investment & Shanghai and Shenzhen 300 index \\
\cline { 2 - 3 } & securities investment funds & Shanghai Stock Exchange Fund Index \\
\hline
\end{tabular}

As shown in the above table, this paper uses an index measure suitable for investment tools. The choice of one-year bank deposit for bank deposit not only reflects the general income of bank deposit, but also has strong liquidity. What's more, the national debt is measured by the Shanghai National debt Index, which can better reflect the overall changes in our bond market. The Shanghai and Shenzhen 300 index is more able to reflect the changes in
China's stock market than other stock indices. Moreover, the securities investment fund is measured by the Shanghai stock fund index, which is the closed-end Fund Index of Shanghai and Shenzhen Trading, which can reflect the overall situation of the fund market.

Descriptive analysis of the rate of return of the above indicators, the average rate of return of each index, variance is shown in chart 3.2 .

Chart3.2 Statistical Analysis of the rate of return of the Index system from January 2015 to June 2019

\begin{tabular}{c|c|c|c|c}
\hline $\begin{array}{c}\text { investment } \\
\text { type }\end{array}$ & $\begin{array}{c}\text { Shanghai and } \\
\text { Shenzhen 300 rate of } \\
\text { return }\end{array}$ & $\begin{array}{c}\text { Shanghai Stock } \\
\text { bond yield of } \\
\text { Shanghai bond } \\
\text { Exchange Fund } \\
\text { Rate of return }\end{array}$ & $\begin{array}{c}\text { Rate of return on } \\
\text { one-year bank } \\
\text { deposits }\end{array}$ \\
\hline mean & 0.0019 & 0.0068 & -0.007 & 0.004 \\
\hline variance & 0.007 & 0.0002 & 0.006 & 0 \\
\hline
\end{tabular}

As shown in figure 3.2, from January 2015 to June 2019, the yield of Shanghai Treasury bonds is the highest, followed by one-year bank deposit interest rate, Shanghai and Shenzhen 300 rate of return, Shanghai and Shenzhen fund rate of return. From the point of view of variance, the smallest standard deviation is the one-year bank deposit interest rate, followed by Shanghai Treasury bonds, Shanghai and Shenzhen 300, Shanghai and Shenzhen funds. If the rate of return and risk are considered at the same time, it is impossible to intuitively determine which financial instruments to invest, so it is necessary to introduce the portfolio model, which fully considers the factors such as the rate of return and risk of financial instruments, and obtains the optimal portfolio of the portfolio with MATLAB software. It is assumed that the rate of return of each investment type is approximately subject to the normal distribution. Chart 3.3 shows some important statistical characteristics of these four investments.

Chart 3.3 optimal portfolio based on CVaR

\begin{tabular}{c|c|c|c|c}
\hline type CVaR & 0.005 & 0.01 & 0.015 & 0.02 \\
\hline bank deposit & 0.27 & 0.2623 & 0.2503 & 0.2312 \\
\hline $\begin{array}{c}\text { Shanghai and Shenzhen } \\
\mathbf{3 0 0}\end{array}$ & 0.0472 & 0.0745 & 0.0915 & 0.2091 \\
\hline $\begin{array}{c}\text { Shanghai Stock Exchange } \\
\text { National debt }\end{array}$ & 0.5213 & 0.4641 & 0.4367 & 0.3164 \\
\hline $\begin{array}{c}\text { Shanghai Stock Exchange } \\
\text { Fund }\end{array}$ & 0.1615 & 0.1991 & 0.2215 & 0.2433 \\
\hline
\end{tabular}




\begin{tabular}{l|l|l|l|l}
\hline rate of return & 0.0073 & 0.0081 & 0.0092 & 0.016 \\
\hline
\end{tabular}

As shown in Table 3.3, taking different risk levels to get different optimal portfolio, on the whole, no matter what kind of risk level, the proportion of stock investment is the smallest, followed by funds, bank deposits, the largest proportion is treasury bonds.In addition, with the increase of $\mathrm{CVaR}$ risk measurement, the rate of return increases, the proportion of investing in stocks and funds increases gradually, and the proportion of bank deposits and treasury bonds decreases.

Chart 3.4 CVaR optimal portfolio with minimum value

\begin{tabular}{|c|c|c|c|c|}
\hline & $\begin{array}{c}\text { Shanghai and } \\
\text { Shenzhen 300 index }\end{array}$ & $\begin{array}{c}\text { Shanghai Stock } \\
\text { Exchange } \\
\text { National debt }\end{array}$ & $\begin{array}{c}\text { Shanghai Stock } \\
\text { Exchange Fund }\end{array}$ & $\begin{array}{c}\text { One-year bank } \\
\text { deposits. }\end{array}$ \\
\hline weight & 0.000 & 0.522 & 0.012 & 0.464 \\
\hline Min CVaR & \multicolumn{4}{|c|}{$\mathrm{CVaR}=0.00013$} \\
\hline rate of return & \multicolumn{4}{|c|}{$\mathrm{R}=0.0026$} \\
\hline
\end{tabular}

As shown in the table above, under the minimum value of CVaR, Shanghai Treasuries account for the largest proportion of one-year bank deposits in the portfolio, in which the proportion of bank deposits is slightly higher than that of treasury bonds. Secondly, the proportion of Shanghai Stock Exchange Fund is relatively small, and the proportion of stocks is 0 . However, in this extreme case, although the optimal portfolio is obtained, the rate of return has also reached the lowest value of 0.0026 . Under the situation of pension development in China, this kind of portfolio isn't recommended.

\section{Conclusion}

By studying the investment status of pension funds in China, it is of great theoretical and practical significance to analyze the investment portfolio of pension funds. Through the above research, this paper puts forward some suggestions on pension investment strategy:

1. The type of investment in the pension should be more abundant, and bank deposits are no longer the most important means of investment. According to the above, the yield of the national debt is higher and relatively stable compared with the bank deposit, the investment proportion should be the highest. The risk of the fund is higher than the national debt, lower than the stock.Its proportion is close to the bank deposit. Moreover, the stock has the characteristics of high risk and high yield, a small amount of money can be put into place.

2. Although large amounts of pension invest in bank deposits and treasury bonds, which can make the risk value small enough to avoid risk, but the yield is not optimistic. At present, there is an obvious funding gap in China's pension, increasing the diversity of investment and increasing the rate of return is an important solution. The number of pension insurance funds in China is huge, so we should allocate the investment category reasonably and increase the rate of return under the condition of taking risks moderately. We should not only focus on the investment with high stability and low return.

3. With the gradual opening of China's financial market and the increasing number of derivative financial products, more and more investors pay attention to how to control the risk. Since the CVaR risk measurement method is more reasonable and effective than the VaR method, it is of great practical significance to use it to measure the market risk.

\section{REFERENCES}

[1] Li Rongxiang. A study on the portfolio Strategy of Insurance funds in China [D]. Anhui Agricultural University, 2017.

[2] Wang Xiaomei. Research on insurance investment strategy based on mean-variance-CVaR model [D]. Shandong University of Finance and Economics, 2017.

[3] Dai Xiang Tong. Research on Investment Infrastructure of China pension Insurance Fund [D]. Shandong University of Finance and Economics, 2017.

[4] Wu Hong, Xu Bin, Li Jie. Social pension Insurance and Family Financial Asset Investment: an empirical Analysis based on Family Microsurvey data [J]. Science of Finance and Economics, 2017 (04): 39 / 51.

[5] Liu Guopei. Research on the investment and financing efficiency of the basic pension insurance fund in tianjin under the background of aging[d]. Tianjin University,2017.

[6] Zhang Xing China Institute of Labor and Social 
Security. Four Strategies for Marketized Investment of China's Basic Pension Insurance Fund[N]. China Labor Security Journal, 20190524(003).

[7] Pan, Lingling, $\mathrm{Xu}$, Bing. The impact on the solvency in non-life insurance industry in China: Based on the investment assets management[P],2013.

[8] Ran $\mathrm{Qu}$, Zhenting Qu. Interaction between Life Insurance Fund Investment and Financial Market in China: General Investment Strategies for Life Insurance Companies[P]. Management and Service Science, 2009. MASS '09. International Conference on,2009.

[9] Daijun Zhang, Wei Chen. Insurance Funds Involved in the Affordable Housing Construction Investment for Risk Management[P]. Business Intelligence and Financial Engineering (BIFE), 2011 Fourth International Conference on,2011.

[10] Zhao Fang, Lu Shan, Li Xiaoyan. A study on the performance of China's pension Insurance Fund Investment Stock Market [A]. (China Center for Insurance and Risk Management of Tsinghua University SEM), Center for China Insurance and risk Management, School of Economics and Management, Tsinghua University (Cass Business School,City University London). 2018 China Insurance, Cass School of Business, City University of London Proceedings of the International Annual Conference on risk and risk Management $[\mathrm{C}]$. China Insurance and risk Management Research Center, School of Economics and Management, Tsinghua University, (China Center for Insurance and Risk Management of Tsinghua University SEM), Cass School of Business, City University, London, (Cass Business School,City University London):, School of Economic Management, Tsinghua University, China Insurance and risk Management Research Center, 8:17.

[11] ZHANG Daijun. The Matthew Effect Formation Mechanism of the Insurance Funds Involved in the Security Housing Construction Investment and the Resolution [A]. (China Center for In, China Insurance and risk Management Research Center, School of Economics and Management, Tsinghua University Surance and Risk Management of Tsinghua University Sem), (Cass Business School,City University London). 2011 International Annual Conference on Insurance and risk Management, Cass School of Business, City University of London [C]. (China Center for Insurance and Risk Man, China Insurance and risk Management Research Center, School of Economics and Management, Tsinghua University. 